Artigos

Marina Caetano'

Maria Raquel Caetano

\title{
Adultilização na infância: as representações das crian- ças dos anos iniciais do ensino fundamental
}

Resumo: $\bigcirc$ artigo faz parte de uma pesquisa realizada em uma escola e busca identificar, compreender e analisar as representações das crianças que frequentam o segundo e quarto ano do ensino fundamental frente à temática "adultilização da infância" tendo em vista que se vive no século XXI, momento no qual muitas mudanças vêm ocorrendo, entre elas mudanças sociais, políticas e econômicas, que interferem diretamente no âmbito educacional e, consequentemente, na formação de alunos e professores para este século. $\bigcirc$ estudo buscou responder em sua narrativa a seguinte questão: quais são as representações das crianças no ambiente escolar frente à adultilização da infância? Para responder a esta questão foram realizados grupos focais com as crianças, no intuito de coletar dados acerca do problema pesquisado. O estudo suscitou a compreensão de que as crianças já conseguem dizer e classificar o que é apropriado para elas e para os adultos.

Palavras-chave: Infância; Mídia; Consumo; Adultilização.

\section{Adultilização Childhood representations: of children of early years of basic education}

Abstract: The article is part of a survey conducted in a school and seeks to identify, understand and analyze the representations of children attending the second and fourth grade of elementary school and the theme "Childhood adultilização" given that we live in the XXI century, at which time many changes have taken place, including social, political and economic, that directly interfere in the education sector and hence the formation of students and teachers for this century. The study sought to answer in his narrative the question: what are the representations of the children in the school front environment to childhood adultilização? To answer this question were conducted focus groups with children in order to collect data about the researched problem. The study raised the understanding that children can already say and classify what is appropriate for them and for adults.

Keywords: Childhood. Media. Consumption. Adultilização.

\footnotetext{
I Pedagoga, cursando especialização e professora no Instituto Sinodal Dorothea Schäfke. E-Mail: marinacaetano972@gmail.com

2 Doutora em Educação pela UFRGS. Professora e Coordenadora do Pós-Graduação do Instituto Federal de Educação, Ciência e Tecnologia Sul-riograndense. E-Mail: caetanoraquel2013@gmail.com
} 


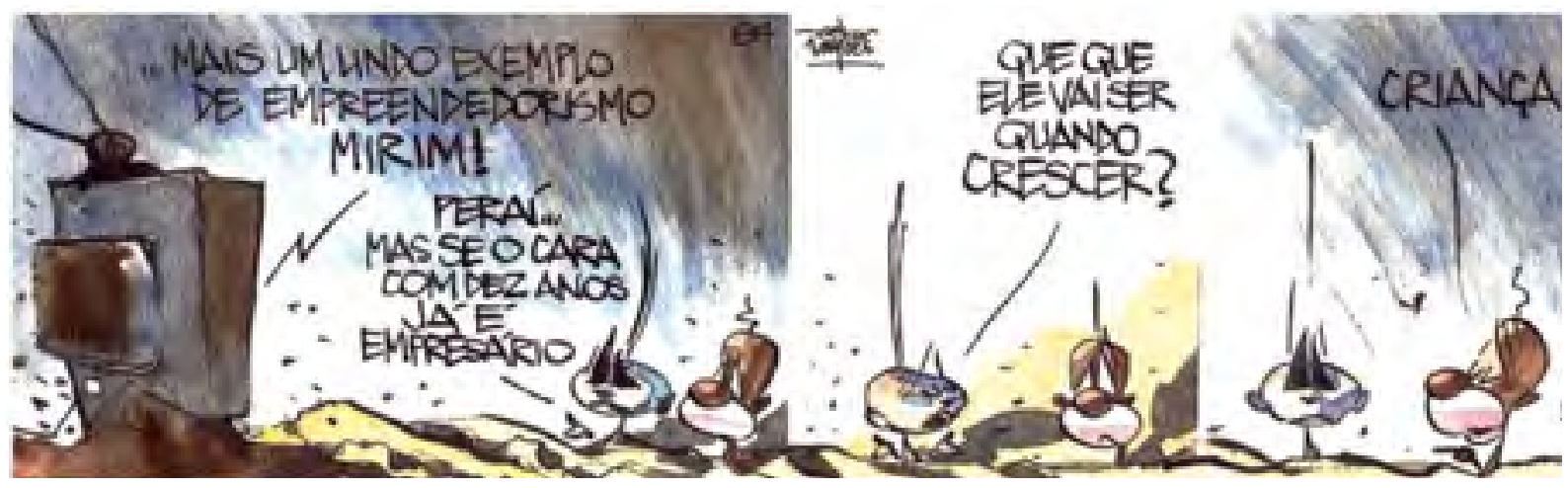

VASQUES, Edgar. Rango. Extra Classe, Porto Alegre. Edição 194. Jun. 2015. Quadrinhos, p. 27.

\section{Introdução}

Alguns autores entendem que a adultilização caracteriza-se pelo surgimento de uma nova configuração de infância, a qual está, sobretudo, construída a partir da lógica de mercadoria e de consumo. Outro fator apresentando veementemente pelos especialistas do assunto é a mudança na relação entre pais e filhos que antes era marcada pela autoridade, muitas vezes confundida com medo e, nos dias de hoje, é marcada pela ascensão feminina no mercado de trabalho, bem como pela utilização da criança como fonte de renda, considerando, nesse caso, os setores de publicitários, a fim de aumentarem a renda familiar.

Compreende-se que o corpo da criança vem sendo alvo de constantes e acelerados investimentos, principalmente quando em frente à televisão assistindo constantemente a comerciais e propagandas. Há, segundo Felipe e Guizzo (2003), uma erótica infantil, ou seja, uma erotização da imagem da criança que é amplamente divulgada pela mídia. Não obstante, encontram-se inúmeras propagandas e anúncios em que a criança é mostrada em poses sensuais ou em contextos de sedução.

A escola e sua função social cujo objetivo é abordar o conhecimento historicamente construído pela humanidade e formar sujeitos político, histórico e social também ocupa um grande espaço nas relações de produção corporal, de consumo e erotização das infâncias atuais. Isso porque o corpo, na escola, vem sendo apresentado para os alunos como um corpo atemporal. Como citam Quadrado e Ribeiro (2005), é um corpo sem rosto, pés, mãos ou sexo, é fragmentado e funcionalista, deslocado do ambiente em que se situa. O corpo produzido pela escola tem sido universal, 
padrão, que se repete independentemente de sua classe, raça ou etnia, não oferecendo espaço para a discussão de outros aspectos que não são biológicos, mas sim de produção cultural. Assim, ao se considerar o corpo na escola, deve-se levar em conta o processo de problematização de um corpo híbrido, que une as esferas biológicas e culturais.

Dessa forma, entende-se que o currículo da escola precisa ser compreendido como um processo de construção social, que perpassa as relações de poder "que fizeram e fazem com que tenhamos esta definição determinada de currículo e não outra, que fizeram e fazem com que o currículo inclua um tipo determinado de conhecimento e não outro" (SILVA, 2002). Nessa perspectiva, os Estudos Culturais definem que o conhecimento é socialmente construído e mantém relações com a produção das identidades, sendo que o currículo atua na construção e reconstrução dessas e também é constituído por elas.

Portanto, levando-se em conta que o corpo e suas identidades são produzidos socialmente a partir da relação estabelecida entre os sujeitos e a sociedade, considerando a escola e seu currículo como meio de produção social desse corpo, através da análise dos múltiplos conceitos para infância, dos elementos que contribuem para tal, a adultilização da infância, visa-se, neste trabalho, responder a seguinte questão: quais são as representações dos alunos no ambiente escolar frente à adultilização da infância? Para isso, uma pesquisa de campo foi realizada em uma escola de educação básica privada da cidade de Taquara, RS, na qual se buscou identificar a percepção e as representações das crianças diante desse questionamento.

\section{Dialogando com os tempos e as infâncias}

Conforme o dicionário Aurélio (2001, p.387), infância é o período de crescimento do ser humano que vai do nascimento à puberdade. De acordo com a história da infância, nem sempre a criança foi cuidada, nem mesmo foi observado seu desenvolvimento por completo. Sabe-se que todos os capítulos da história da infância foram registrados a partir do olhar adulto, pois a criança não pode registrar sua própria história. Certamente, se fosse dada voz a elas, as histórias seriam de momentos de alegria e amorosidade vividos, ou até mesmo atos de injustiça e tristeza, de desencantos com a vida que leva. No decorrer dos séculos, existiram divergentes concepções de criança.

Buscando novamente um significado à palavra infância, eis que se encontra uma nova de- 
finição, oriunda do latim infantia, que significa "incapacidade de falar". Esse conceito está extremamente ligado à Antiguidade. Nessa época, a concepção de criança era baseada na inexistência de uma consciência infantil. Eram vistas como pequenos adultos, porque elas tinham uma função utilitária à sociedade, sendo incluída à vida adulta logo cedo como qualquer operário da época. A relação dos adultos com as crianças da época era sem discernimentos, pois conversavam naturalmente sobre todos os tipos de assuntos, vulgares ou não, inclusive as inseriam em jogos sexuais. Segundo Ariès (1981, p.51), "no mundo das fórmulas românticas, e até o fim do século XIII, não existem crianças caracterizadas por uma expressão particular, e sim homens de tamanho reduzido".

Dessa forma, mudanças com relação aos cuidados com a criança só vieram a ocorrer anos mais tarde, com a interferência do poder público e a preocupação da Igreja em proibir crimes contra menores. Ficavam, então, as crianças sob responsabilidade principalmente das mulheres. Sendo assim, de acordo com a Igreja Católica, no século XIV, as crianças passam a ser tratadas como anjos, associando-as ao menino Jesus e a Virgem Maria.

Transformações sociais, políticas e econômicas ocorrem assiduamente, todas elas sempre ligadas à relação entre pais e filhos, tendo a família um papel importantíssimo na educação desses. Assim, surge o sentimento de infância, que logo foi devastado pela Revolução Industrial, que levou as crianças novamente ao mercado de trabalho.

Entre os anos de 1850 e 1950, o desenvolvimento das ciências humanas levou a retirada das crianças de seus locais de trabalho e a promoção da inserção em contextos agentes de aprendizagem. A família passa novamente a ter um papel importante na formação das crianças, de forma a assegurar seus direitos, deveres, bem-estar e cuidados físicos.

A contemporaneidade se faz presente, e o espaço continua permanentemente mutante, atribuindo a essa nova época uma diferente noção de infância que agora incorpora outras características ditadas também pela globalização e pelo neoliberalismo. Não obstante, passa-se a considerar que a infância não representa uma fase singular do ser criança, mas que as marcas históricas constituirão diferentes infâncias e modos de ser criança, porque não existe uma única infância ou uma única criança, e sim diferentes infâncias e crianças em mesmos espaços, as quais são resultados de realidades díspares que estão em constante confronto. Sarmento (2001) diz que as crianças são globalizadas e, segundo ele, é esse movimento que as torna semelhantes, deixando de lado uma análise 
mais profunda de suas singularidades. O autor analisa as mudanças contemporâneas que implicam no estatuto social da infância e que perpassam as legislações que regulam as instituições, a criação de um mercado de produtos para a infância, a influência de programas de televisão de cunho internacional e a institucionalização dos cotidianos infantis, principalmente com a difusão das escolas.

Dessa forma, chega-se a um ponto crucial dessa discussão. Apontado por Sarmento (2001); Pinto e Sarmento (1997) em pelo menos duas de suas implicações que provocam mudanças na visão de infância, a mídia tem tido significativa contribuição como elemento na formação direta das crianças do novo século. Parafraseando o verbete do dicionário Aurélio (2001) relacionado à mídia, pode-se dizer que ela é compreendida como qualquer dispositivo (revistas, televisão, computador, livros, etc.) capaz de se relacionar, aos processos de construção de ideias, valores e comportamentos sociais. Ou seja, a mídia atua como um artefato cultural de aprendizagem informal, pois difunde conteúdos que podem produzir um infinito número de efeitos no comportamento humano e principalmente infantil.

Logo, a sociedade atual está diante de uma realidade em que os meios de comunicação utilizam da ingenuidade das crianças não apenas como alvos do consumo exacerbado e inconsciente, mas também como forma de inseri-las precocemente no mundo adulto. Assim como na Antiguidade, hoje em dia a criança tem sido adultilizada.

Os corpos das crianças vem sendo alvo de constantes e acelerados investimentos, principalmente quando em frente à televisão assistindo constantemente a comerciais e propagandas. Segundo Felipe e Guizzo (2003),

Tatiana Landini (2000, p. 29) chama atenção para o fato de haver uma erótica infantil, isto é, uma erotização da imagem da criança, amplamente veiculada pela mídia. Não é difícil encontrar propagandas e anúncios onde a criança é mostrada em pose sensual ou em um contexto de sedução.

Além disso, a moda também ocupa um grande espaço nas relações de consumo e erotização das infâncias atuais. A mídia estabelece o que é mais fashion, podendo tornar o modelo de hoje o cafona de amanhã. Assim, a moda, como um fenômeno mundial, é um meio de interação e comunicação social que possui inúmeras ilustrações.

Nesse sentindo, percebe-se que, ao longo dos anos, as diversas marcas, antes somente para 
o público adulto, criam roupas e acessórios de adultos para crianças, como é o caso das minissaias, sapatos de salto, estojos de maquiagem e tudo aquilo que faz o corpo da criança aparecer para, então, consumir cada vez mais. Assim, entende-se que as meninas são os principais alvos dessa cultura adultilizada e erotizada da moda. Exibem-se com unhas pintadas, cabelos mechados, calçados de salto e principalmente muita maquiagem. Os meninos, por sua vez, utilizam roupas, óculos e tênis, muitas vezes oriundos do mundo adulto. Pode-se perceber ainda a enorme fixação dos garotos por aparelhos eletrônicos e jogos de videogame que possuem classificação acima da sua idade.

Entendem-se como crianças adultilizadas e erotizadas aquelas "retratadas com expressões sérias, utilizando roupas com estampas sóbrias, características do universo adulto" (ORLANDI, 2012), bem como aquelas que utilizam acessórios habitualmente utilizados por adultos, ou imitam comportamentos como estar com as mãos no bolso e pernas cruzadas de forma elegante. Ainda trazem "elementos que remetem à sutil sensualidade, quer pelo uso de adereços, maquiagem e esmaltes de cores intencionalmente mais fortes, roupas insinuantes ou partes do corpo à mostra que transmitem um apelo sensual discreto, quer pelos gestos que induzem a um certo romantismo" (ORLANDI, 2012), geralmente encontrado em protagonistas meninas.

Não há como falar de moda e beleza sem discutir sobre sexualidade, principalmente quando se diz respeito as crianças. Percebe-se que, diante dos fatos apresentados e das pesquisas realizadas, há uma intensa aceleração da puberdade e da sexualização, antes mesmo da adolescência, fazendo com que crianças parem de brincar e praticar outras atividades que são elementares para infância, ocorrendo o que se chama de adultilização da infância.

Segundo Landini (2000), não é difícil encontrar propagandas nas quais as crianças são mostradas em poses sensuais em um contexto de sedução. Exemplos estão em artefatos culturais bem atuais, como é o caso de revistas de moda infantis, comerciais de televisão e até mesmo banners e panfletos, os quais mostram muito bem essa ideia de erotização dos corpos infantis, estabelecendo um combinado de ingenuidade e sedução que, de certo modo, podem influenciar práticas de pedofilia. Mas se sabe que a preocupação com a aparência do corpo não é de hoje, não só as mulheres maduras, mas também das crianças. Segundo Borges (2007):

Este fenômeno tem sido observado por pais, educadores e psicólogos, e é expressa, no limite, no surgimento de distúrbios como a anorexia e a bulimia em crianças cada vez mais jovens. Submetidas às mesmas pressões exercidas sobre os adultos, sob as injunções dos mecanismos do mercado dirigido ao corpo, as crianças e jovens, principalmente do sexo 
feminino (embora os meninos também sejam envolvidos), procuram, cada vez mais cedo, incorporar os modelos da última moda. (BORGES, 2007, p.96).

É na produção midiática e em seus produtos resultantes que a centralidade do corpo e da sexualidade, como já foi citada anteriormente, aparecem explicitamente. Além disso, as representações sobre o corpo ao lado da sexualidade apresentam-se como parte dos conteúdos das culturas infantis atuais, criadas e mediadas pelos adultos, com o propósito de fazer as crianças consumirem cada vez mais.

Diante do contexto apresentado anteriormente, buscam-se relacionar esses dados com a realidade escolar e com o currículo contemporâneo nos quais o conhecimento é socialmente construído e mantém relações diretas com a produção de identidades e com as representações. Identidades são definidas por Woodward (2012) como um sistema de classificação não unificado, contendo contradições e marcações simbólicas que sempre consideram o espaço cultural no qual se está inserido. Já as representações, ligam-se diretamente às identidades e incluem, de acordo com a mesma autora, práticas de significação e os sistemas simbólicos por meio dos quais os significados são produzidos, dando sentido à experiência e àquilo que o homem é.

Pode-se dizer que o currículo é também uma representação das identidades e da cultura de um determinado grupo de pessoas. Assim, conforme Silva (2002), ele precisa ser entendido como um processo de construção social, não podendo ser compreendido apenas a partir de relações de poder "que fizeram e fazem com que tenhamos esta definição determinada de currículo e não outra, que fizeram e fazem com que o currículo inclua um tipo determinado de conhecimento e não outro" (Silva, 2002, p. 135).

$\mathrm{Na}$ contemporaneidade, surge o conceito de que não há apenas um "jeito de ser criança", mas sim, múltiplos. Frases como "Todas as crianças agem assim” ou "Criança é assim mesmo", nesse caso, não podem ser atribuídas, já que a pesquisa utiliza um conceito mais amplo e plural que, de acordo com Corsaro (2011), Barbosa (2007) e Sarmento (2001), pode ser caracterizado pela sua capacidade de observar, apreender e interpretar rapidamente as diferenciações sociais, complementando que ela é parte de uma categoria geracional na qual se fazem presentes as diversidades e as desigualdades da sociedade contemporânea.

Compreende-se que não mais apenas os adultos passam a serem alvos da sociedade atual ca- 
racterizada pelo consumo exacerbado, mas também jovens e, principalmente, crianças. Ao mesmo tempo em que o adulto busca intensamente sua jovialidade perdida, a criança busca incansavelmente ser um adulto. Assim, as gerações acabam igualando-se em um só modo de vida contemporâneo.

Entende-se que o ser humano não é apenas corpos que se desenvolvem sem um foco, mas também se compreende que o meio forma indivíduos. E, dessa forma, a mídia e os meios de comunicação de massa entram em contato com o mundo infantil, influenciando seu jeito de ser, sentir e, até mesmo, de se vestir. Tanto a partir do referencial teórico utilizado quanto na análise a ser realizada, percebe-se que a criança pode ser observada de inúmeras formas. Para este trabalho, as duas formas principais são a criança erotizada e a criança adultilizada.

\section{Escolhas metodológicas: alguns pressupostos}

A escola, a família e a sociedade, como um todo, têm a responsabilidade na formação das crianças. Nesse contexto, considera-se que deve focar sua atenção aos impactos impostos pelas representações sociais conduzidas pela mídia, como forma de preservar valores infantis e conceitos que possam prejudicar seu amadurecimento, que ocorrerá, provavelmente, de maneira precoce, descaracterizando a infância e transformando todos em adultos em miniatura.

Como representação social, compreende-se o termo adotado por Meyer (2000) o qual atende às práticas de significação linguística e cultural e aos sistemas simbólicos através dos quais os significados são construídos. Assim, cabe-se ressaltar que as identidades são construídas culturalmente e estão fortemente vinculadas às práticas sociais, das quais, segundo Hall (apud FELIPE, 2007), toda a prática social depende e tem relação com o significado de cultura, já que ela é uma das condições de existência para essa prática, tendo, ainda, caráter discursivo.

A sociedade é dotada de inúmeras práticas sociais já que também é meio de representação da cultura que se construiu e se constrói à medida que o tempo discorre. Se a sociedade, enquanto agente na construção de identidades, possui determinada responsabilidade acerca das vivências infantis, a criança, dotada de sua multiplicidade, erotizada e adultilizada, em idade escolar, passa a ser não só uma preocupação da escola em que ela está matriculada, mas de outras áreas de aprendizado. Segundo Shirley Steinberg e Joe Kincheloe (1997, apud FELIPE, 2007), essas áreas são chamadas de Pedagogias Culturais, as quais abrangem uma variedade de locais que envolvem situações de 
ensino e aprendizagem, mas que não estão, necessariamente, vinculados à escola. Elas incluem bibliotecas, televisão, cinemas, jornais, revistas, brinquedos, propagandas, videogames, livros, entre outros.

Dentre os inúmeros desafios contemporâneos e incertezas no campo educacional, estão questões cada vez mais complexas. A psicologia do desenvolvimento e a pedagogia já não conseguem mais explicar as infâncias e as múltiplas culturas infantis na contemporaneidade. As crianças que já foram consideradas seres "sem voz", hoje, possuem seu significado ligado as suas subjetividades e também as culturas reproduzidas interpretativamente, como cita Corsaro (2011).

Com base na ideia de reprodução interpretativa, Barbosa (2007) explica que a reprodução, nesse caso, ocorre por conta de sua participação efetiva na sociedade, forçada por sua participação nas diversas instituições sociais, culturais e políticas a se tornar semelhante. Por outro lado, a palavra interpretativa salienta que as crianças não apenas internalizam a cultura, como citam as teorias tradicionais, mas são participantes ativos na construção e na mudança cultural de toda a sociedade.

A escola como instituição social, cultural e política, hoje em dia, tem o papel de preocuparse não somente com os conteúdos, mas também com o que é considerado "oculto" no currículo. O currículo oculto representa uma parte implícita no processo educacional e é aquilo que não pode ser medido e avaliado, entretanto, faz parte do cotidiano escolar e reforça o aprendizado mútuo do aluno e do professor.

Para Gonçalves (1994), o aprendizado dos educandos não está restrito apenas aos aspectos formais da aprendizagem materializados no que se chama de currículo ou planos de estudos, pois não há neutralidade no processo de ensino e aprendizagem. Isso acontece porque toda a ação que envolve os processos de ensino e aprendizagem é complexa e se difere em cada instituição que possui seus próprios currículos ocultos de acordo com suas necessidades.

\section{I A pesquisa}

A pesquisa foi realizada em uma escola de educação básica privada da cidade de Taquara, RS e se dividiu em três etapas básicas. O ponto de partida consistiu na apresentação do projeto de pesquisa à coordenação pedagógica. A segunda etapa da pesquisa partiu do pressuposto de que existem múltiplas infâncias e que essas se desenvolvem nos seus diferentes tempos, espaços e contextos, 
tendo em vista sua característica mutável, de sujeito em transformação e, portanto, ativa em sua ação sobre o mundo que a cerca. Sendo assim na coleta de dados foi utilizado o procedimento do grupo focal com os alunos do Ensino Fundamental I, das turmas de segundos e quartos anos.

Os alunos são sujeitos da pesquisa e com base em recentes descobertas teórico-metodológicas para a realização de pesquisas com crianças, diferente de pesquisas anteriores que deixam na penumbra as crianças como seres plenos e na escuridão a infância como categoria social. Sustenta-se nesta pesquisa, como citam Pinto e Sarmento (1997), a indispensabilidade da mobilização interdisciplinar capaz de compreender e interpretar as múltiplas variáveis dos fatores que constroem a infância. Sendo assim, apresenta-se como objetivo específico desta pesquisa descrever e analisar a percepção das crianças diante do tema proposto, considerando-as protagonistas desse processo. Como aponta Sirota (2001), trata-se de compreender aquilo que a criança faz de si e aquilo que se faz dela, e não simplesmente aquilo que as instituições inventam para ela.

Como procedimentos metodológicos para a pesquisa com as crianças, utilizou-se da escuta atenta e olhar aguçado durante quatro encontros, que aconteceram mediante autorização dos pais, durante 30 minutos para cada encontro, duas vezes por semana, no horário de aula, definido pela escola a ser pesquisada e com a presença de pelo menos um acompanhante, sendo esse um monitor, professor ou coordenador. Esse procedimento pode ser caracterizado como grupo focal, tendo em vista que é uma técnica de coleta de dados qualitativos que se dá por meio de entrevistas grupais, apropriada para esse modelo de pesquisa, a qual busca entender atitudes, preferências, necessidades e sentimentos relacionados a um determinado foco, que, nesse caso, é a adultilização na infância.

$\mathrm{Na}$ escolha dos alunos foram considerados dois critérios: diferenças de um ou dois anos de idade entre os anos e também que os alunos soubessem ler e escrever para, consequentemente, interpretar e representar os conteúdos apresentados. Outro fator importante na escolha das turmas foi a marcação que ocorre na escola pesquisada entre os primeiros e segundos anos do Ensino Fundamental I, em que os alunos migram da Unidade II, a qual abrange turmas do maternal ao primeiro ano, para a Unidade I, onde estudam os alunos do segundo ano do Ensino Fundamental ao Ensino Médio. 


\section{As representações dos alunos sobre a adultilização}

De acordo com a Lei 8.069 que institui o Estatuto da Criança e do Adolescente (ECA), considera-se criança a pessoa até doze anos de idade incompletos, que goza de todos os direitos fundamentais inerentes à pessoa humana e possui a condição peculiar de pessoa em desenvolvimento. Percebe-se que se vive em uma sociedade cada vez mais globalizada e conectada. As crianças, ainda em desenvolvimento, constituem-se nesse meio e interligam diferentes culturas como as instituídas na família, na escola, nos clubes e na mídia.

De acordo com Barbosa (2007), não se pode mais falar em "cultura" no singular e sim em diversas e diversificas "culturas", no plural. Mais do que isso, não se pode mais ignorar que as crianças são seres construtores de suas próprias culturas e possuem seus próprios conceitos, significados e problemáticas.

\footnotetext{
Elas elaboram sentidos para o mundo e suas experiências compartilhando plenamente de uma cultura. Esses sentidos tem uma particularidade, e não se confundem nem podem ser reduzidos àqueles elaborados pelos adultos; as crianças têm autonomia cultural frente ao adulto. Essa autonomia deve ser reconhecida e também relativizada: digamos, portanto, que elas têm uma relativa autonomia cultural. Os sentidos que elaboram partem de um sistema simbólico compartilhado com os adultos. (COHN, 2005, p. 35).
}

A presente pesquisa se deu a partir da análise e da compreensão desses conceitos, estabelecendo uma relação entre as culturas nas quais as crianças são e estão inseridas e as culturas construídas por elas mesmas, a fim de tematizar, principalmente, a questão contemporânea da adultilização da infância sob diferentes olhares. Ainda, buscou-se abordar, nos grupos focais, as temáticas do consumo e da erotização.

\section{I O grupo focal}

O primeiro dia da realização do grupo focal foi esperado com muito entusiasmo pelos alunos convidados para a pesquisa. As professoras selecionaram cinco meninos e nove meninas, ou seja, quatorze alunos no total, com autorização dos pais e identificados, nesta pesquisa, com nomes fictícios. Os educandos foram divididos em dois grupos: o primeiro abrangeu apenas os alunos do segundo ano do Ensino Fundamental I, que ficou com seis meninas e um menino; e o segundo, que abrangeu os alunos do quarto ano do Ensino Fundamental II, composto por quatro meninos 
e três meninas.

Uma característica comum a todos os alunos participantes dos grupos selecionados é que todos estudam desde a educação infantil na escola. Outra diz respeito à idade, já que todos possuem de sete a nove anos.

O primeiro encontro baseou-se na apresentação de imagens, apreciação e reconhecimento de marcas, estilos e modelos. As imagens consistiram em fotos de diversas revistas, de campanhas publicitárias ou não, nas quais apareciam crianças enquadradas na tabela de Orlandi (2012): travessa, sonhadora, erotizada, adultilizada, típica, consumista, esperta e inocente. Após, os grupos construíram um cartaz no qual realizaram a classificação entre o que são "coisas de adulto", "coisas de criança" e "coisas de todos". De forma abrangente, foram trabalhadas quatro significações: o que é produto, o que é consumo, o que é ser adulto e o que é ser criança.

Pesquisadora - Comprar é coisa de adulto ou de criança?

Aluno $1-$ É dos dois!

Aluno 2 - De adulto!

Aluno 3 - É de todos!

Aluno 4 - Porque criança compra brinquedos, compram roupa...também sapato!

Aluno 5 - Eu sempre gasto todo meu dinheiro. E minha mãe não deixa eu comprar tudo... (Grupo 2)

Aluno 4 - Isso não é de criança, é de adulto! Por que salto alto não se usa, colar deste tamanho, criança não fica nessas placas enormes de loja e não fica pelada assim! Nem toda maquiada assim forte!

Aluno 6 - Isso é um miniadulto ou isso é uma criança? - colocando a mão na cabeça em dúvida.

\footnotetext{
Aluno 3 - Parece uma miniadulta!

Aluno 7 - Eles copiaram uma roupa de adulta pra menina.

(Grupo 2)
} 
Aluno 11 - Sem dúvida criança! Ele tá com uma blusa do homem aranha e brincando com doces!

Aluno 8 - Ele tá fazendo bagunça!

Pesquisadora - Então bagunça é uma coisa de criança?

Todos menos Aluno 9 - Sim!

Aluno 9 - Adulto também!

Aluno 8 - Adulto também faz, mas criança faz muito mais...

Aluno 12 - Depende da bagunça...

Aluno 10 - Mas ali ele tá brincando!

Aluno 13 - Bagunça de criança é brinquedo, bagunça de adulto é roupa...

Aluno 8 - Maquiagem...

Aluno 9 - Trabalho...

Aluno 12 - Papel de trabalho...

Aluno 13 - Mas eu também tenho bagunça de maquiagem... a cada uma semana eu preciso arrumar de novo!

Aluno 9 - Então vou colocar aqui que bagunça de brinquedo é de criança e bagunça de trabalho de adulto.

(Grupo 1) 
Pesquisadora - O que é ser adulto?

Aluno 5 - Fazer trabalho?

Aluno 6 - Limpar a casa, cuidar da casa, viajar...

Aluno 7 - Mas criança também viaja...

Aluno 2 - Cuidar das coisas, comprar coisas...

Aluno 3 - Tudo que já falaram...comprar coisas, fazer coisas, ir pro trabalho.

Aluno 5 - Eles também sabem dirigir carro!

Aluno 6 - Comprar roupa, comprar comida!

Aluno 4 - Pra mim, ser adulto é trabalhar, tocar, é fazer coisas que crianças não podem fazer e crianças fazem coisas que adulto não pode fazer...

Aluno 2 - Tipo uma coisa que eu não posso falar!

Aluno 4 - Criança não pode dirgir, mas adulto pode. Adulto não pode entrar em lugares pequenos, mas criança pode! E outras coisas... criança não pode trabalhar, adulto pode.

Aluno 1 - Eu não sei!

Pesquisadora - O que é ser criança?

Aluno 6 - Brincar, fazer tema, ir pra escola...

Aluno 1 - Ir à escola, brincar, fazer os temas e deu!

Aluno 5 - Brincar de guerrinha!

Aluno 4 - Criança é brincar, fazer bagunça, passear, andar de bicicleta mais tempo que os adultos... Pesquisadora - Por quê?

Aluno 4 - Porque os adultos não têm muito tempo para andar de bicicleta, eles têm bastantes coisas para fazer... também...

Aluno 7 - Crianças tem o tempo livre! Mas às vezes, elas têm muitas coisas pra fazer

Aluno 5 - Como nós hoje!

Aluno 3 - Brincar, ir na escola...

Aluno 5 - Fazer bagunça com os primos, os irmãos, todo mundo junto!

Aluno 6 - É simples, é só fazer tudo que a gente já fez na vida!

Aluno 4 - Ser a gente!

(Grupo 2)

A questão da significação entre o ser adulto ou criança foi, aparentemente, para os alunos uma temática de fácil associação, porém, quando questionados sobre os papéis sociais que têm adultos e crianças na sociedade, confundiram-se, já que por vezes muitos adultos assumem-se como crianças e, por vezes, crianças atuam como adultos. Algumas palavras e expressões, consideradas sua frequência e ordem de evocação, puderam ser livremente associadas pelas crianças a adultez, são elas: trabalho, responsabilidade, organização, salário, dirigir, viagem e por fim, brincadeira.

Durante a conversa, os alunos explicitaram que seus pais são adultos porque "cuidam da casa", "pagam as contas", "trabalham", “dirigem” e que essas são "coisas" que somente os adultos realizam. Por outro lado, os alunos consideram importante que ajam como adultos na hora de ter responsabilidades com seus "temas de casa", com a organização dos seus quartos e brinquedos e, 
principalmente, a responsabilidade de ir à escola.

Embora haja diferenças aparentes entre o "ser adulto" e o "ser criança", durante a evolução desta pesquisa considerou-se a fala de Sarmento (2005), o qual considera que adultos e crianças vivem um processo intenso e contraditório, que não se esgota e é continuamente atualizado na prática social e nas interações. Entendendo, assim, que fazem parte do processo de identificação e representação de adultos e crianças as variações demográficas, as relações econômicas e seus diferentes impactos nos diversos grupos etários, nas suas memórias, nas práticas sociais e nos estilos de vida de uns e outros.

Pesquisadora - E o que é ser adulto?

Aluno 11 - Ser adulto é... ah, não sei!

Aluno 9 - Eu sei!

Aluno 10 - Eu sei! Ser responsável!

Aluno 12 - Não faltar no trabalho..

Aluno 14 - Não sei...

Aluno 11 - Ter filhos!

Aluno 12 - Não precisa!

Aluno 8 - Cuidar da casa!

Aluno 9 - Ser adulto é usar coisa que criança não pode usar.

Aluno 14 - Ou ver coisas que crianças não podem ouvir...

Aluno 8 - Ser adulto é seguir o que aprendeu na infância pra fazer quando for adulto..

Pesquisadora - E o que é coisa de criança?

Aluno 12 - Brincar...

Aluno 13 - Estudar...

Aluno 10 - Ir na escola!

Aluno 14 - Jogar videogame!

Aluno 8 - Correr e pular, não ficar só no Iphone!

Pesquisadora - Jogar no celular não é coisa de criança?

Aluno 8 - Não, porque criança nasceu pra correr, brincar, pular... jogar...

Aluno 12 - É porque criança não fica o tempo todo no celular...

Aluno 12 - Boa ideia!

Aluno 9 - ...má ideia que inventaram no mundo!

Aluno 14 - Foi muito bom!!!

Pesquisadora - Até que idade é ser criança?

Aluno 13 - Doze! Não, Quinze!

Aluno 14 - Dezoito!

Aluno 11 - Eu acho que até a pré-adolescência! Então até catorze! puberdade!

Aluno 13 - Eu não entendo porque a diretora falou que a partir dos dez anos começa a

“Trabalho" foi outro tema discutido assiduamente durante o primeiro encontro, já que os 
entrevistados consideraram trabalho não só os adultos saírem de casa e irem para os seus "trabalhos formais", como um escritório, mas que eles, enquanto crianças, "trabalham” junto com seus pais nos afazeres domésticos, como lavar a louça, recolher seu prato na hora do almoço e arrumar a cama. Lembraram, ainda, que não são remunerados por isso como seus pais, portanto é uma relação de responsabilidade maior ou menor.

Pesquisadora - E por que uma criança está usando uma roupa de trabalho e maquiada? Aluno 7 - Ela tá maquiada com um batom marrom. Criança não dá pra usar batom marrom porque é muito sem graça e escuro.

Aluno 6 - Não sei! Mas ela não trabalha!

Aluno 7 - É pra imitar o pai!

Pesquisadora - E será que foi a criança que quis colocar essa roupa?

Aluno $4-\mathrm{Eu}$ acho que os dois!

Aluno 7 - O pai!

(Grupo 2)

Aluno 13 - Elas estão usando roupas de adultos!

Aluno 12 - Imitando o pai!

Aluno $14-\mathrm{E}$ as meninas imitando a mãe!

Aluno 12 - As roupas são iguais, mas uma é maior e a outra é menor!

Aluno 13 - O que muda é que pra criança o vestido precisa ser solto e pro adulto colado!

Aluno 11 - As crianças estão querendo ser adultos!

(Grupo 1)

O segundo encontro do grupo focal foi marcado pela temática da adultilização. Foram apresentadas aos participantes imagens publicitárias impressas que mostram pais e filhos vestindo-se de forma semelhante a partir das quais, em grupo, foram realizadas apreciações e discussões. Estas imagens foram apresentadas ao grupo sem prévia explicação da temática, sendo apenas solicitado que os alunos expressassem suas impressões sobre as elas enquanto eram mostradas. As crianças realizaram de forma rápida a leitura das mesmas, as quais eles buscavam descrever com detalhes, inclusive interpretando o "subentendido".

Mostrar aos alunos fotos em que aparecem representações midiáticas de adultos e crianças, geralmente no papel de pais e filhos, provocou a reflexão dos alunos sobre como estão se comportando crianças e adultos. Dessa forma, eles, com estranheza no olhar, perceberam crianças, muitas 
vezes mais novas, vestindo-se como seus pais e como a mídia vem estimulando esse hábito.

A temática da adultilização é discutida assiduamente em Ferreguett (2014), que a considera como um processo que envolve crianças, adultos, o meio em que vivem, e a mídia. Considera também que erotização e adultilização são conceitos indissociáveis que possuem significados muitas vezes subjetivos, podendo ser considerado positivo ou negativo para uma ou outra pessoa.

Quanto as imagens mostradas, foi levantada pelos alunos a questão de que personagens midiáticos, como, por exemplo, super-heróis, "são para todas as idades", tornando a discussão polêmica: "por que adultos podem utilizar roupas e acessórios infantis, mas crianças são crianças!". A colocação das crianças quanto ao assunto rememora a leitura de Postman (1999), que considera a infantilização do adulto como um fenômeno social, o qual recebe contribuições da publicidade, da mídia e da indústria do consumo, que concomitantemente atua a favor do processo de adultilização das crianças.

Aluno 10 - As crianças estão querendo imitar os pais...

Aluno 14 - Mas os pais podem estar querendo imitar as crianças também!

Aluno 12 - E se o filho colocou antes?

Aluno 11 - Não, porque o pai acorda mais cedo e se veste primeiro!

Aluno 13 - Mas olha aquela sunga do personagem que parece um rato... ele é um personagem infantil que os adultos podem usar!

Aluno 11 - Não tem idade, qualquer um pode usar! Tipo, tem homem que usa capa de super-homem... E é normal!

(Grupo 1)

Percebe-se a partir das falas dos alunos que há uma tendência intensa de "imitar" pais, mães, irmãos ou primos (geralmente mais velhos) e atores que aparecem na televisão. Mas, também, fica explícito que há uma indução dos pais, principalmente, no modo de vestir-se, para que as crianças vistam-se como adultos ou de forma adultilizada, respeitando aquilo que é apresentado em artefatos midiáticos.

Morin (2011), ressalta a necessidade do ser humano utilizar-se do lazer ou do jogo para dar sentido à sua existência, e através deste espetáculo, a cultura de massa cria mundos nos quais o impossível pode se tornar real. Esta colocação pode explicar a necessidade de imitação que há entre os pares. A cultura de massa e os artefatos midiáticos são produtores e fornecedores de imagens que 
dão forma ao "impossível” desejado pelas pessoas e que fará um movimento dialético entre o real e o imaginário, e o imaginário e o real.

Aluno 12 - Eu imito meu pai naquilo que ele faz de melhor: jogar futebol!

Aluno 13 - Na minha casa não acontece porque minha mãe não usa maquiagem... não se arruma! Eu imito mais minha prima de 15 anos!

Aluno 14 - Eu não imito, mas meu irmão me imita porque ele é mais novo.

Aluno 11 - Lá em casa o meu irmão mais novo também me imita, faz tudo que eu faço!

Aluno 14 - É porque ele gosta de ti, né, o maluco!

Aluno 12 - Mas eu tenho roupas iguais ao meu pai, quer dizer, cuecas, só que foi a mãe que comprou!

Aluno 11 - Eu tenho camisetas de time iguais as do meu pai!

Aluno 13 - Eu nunca tive e prefiro não sair igual!

Aluno 11 - Mas é sempre minha mãe que compra!

(Grupo 1)

Aluno 10 - Eu achei tudo de adulto! A maioria!

Pesquisadora - Mas então por que as crianças estavam fazendo coisas de adulto?

Júlia - Não sei!

Aluno 8 - Porque as crianças querem ser adultas muito rápido...

Aluno 9 - A criança quer ser a imitação do adulto!

Aluno 10 - Mas às vezes uma pessoa tem 20 anos e ficou pequena....

Aluno 9 - A criança quer seguir o exemplo da mãe...

Pesquisadora - E do pai? Também?

Aluno 10 - É sim!

Aluno 11 - É, eles sempre querem ser iguais ao pai e a mãe.

Aluno 14 - Se o pai e a mãe se vestirem assim, as crianças vão ser assim...

(Grupo 1)

Contrapondo as proposições acima, alunos do grupo focal mostraram em suas colocações que existem pais que não estimulam os filhos a uma vida adultilizada, muitas vezes, pedindo para que esses "façam coisas de criança". É inegável que o "imitar" os adultos faz parte do processo de desenvolvimento das crianças, sendo um momento em que elas selecionam aquilo que consideram importante reproduzir no seu jeito de ser e agir em sociedade. É nas suas múltiplas infâncias que as crianças construirão inúmeras aprendizagens e produzirão papéis que serão levados a sua vida adulta.

O quarto dia de grupo focal abrangeu a temática da erotização. Com duração de aproximadamente trinta minutos, no último dia de interação e coleta de dados com os alunos, foram apresen- 
tadas imagens publicitárias em que apareciam diversas situações cotidianas e outras nem tanto, com crianças. As imagens foram escolhidas de acordo com a tabela de análise criada por Orlandi (2012), na qual ele define crianças "normais", adultilizadas e erotizadas.

Com "Crianças curtindo a vida" e "crianças não curtindo a vida" iniciou a discussão no último dia de grupo focal. Para eles, "curtir a vida" sendo criança não é possuir os melhores brinquedos e muito menos as melhores roupas, mas sim estar com os amigos, brincar e ser feliz. "Trabalho" foi, novamente, uma palavra muitas vezes utilizada pelos alunos, sempre remetida ao fato de que é uma exigência do mundo adulto e não da criança, que possui como "único trabalho os estudos".

O ponto de vista mostrado pelos alunos entrevistados do que é uma criança adultilizada ou erotizada confronta-se com os conceitos apresentados na tabela construída por Orlandi (2012). Nela, as crianças adultilizadas e erotizadas são caracterizadas como tristes, acham sua "vida chata" e não se divertem ou, como citaram os próprios alunos, "com cara de um adulto que se acha".

De acordo com suas falas e representações, a maioria dos alunos não se identifica com as fotos de crianças adultilizadas e erotizadas, mas, sim, com aquelas que se aproximam mais do jeito típico de ser criança: com um olhar alegre e ao mesmo tempo curioso. Porém, de forma significativa, meninos e meninas falaram de momentos em que se sentem adultilizados, principalmente por estarem "maquiados" e vestindo roupas e acessórios fashion, como é o caso dos desfiles de lojas de roupas infantis para os quais são convidados e em fotos de estúdio, a pedido, principalmente, das mães, que, em grande parte, são curadoras de eventos que evidenciam o mundo fashion.

Diante das representações dos alunos perante os grupos focais realizados, pode-se perceber que muitos discursos veiculados pela mídia contribuem significativamente para a formação de suas identidades, considerando que são mais um dos espaços educativos frequentados que ditam e produzem conhecimentos sobre a vida, os comportamentos, os gostos e estilos.

É sabido que a mídia, em geral, tem ocupado um lugar importante na formação das crianças, e isso foi constatado nesta pesquisa. Mas, se pode perceber que, nos comentários apresentados pelos alunos, ela tem atuado significativamente também na vida de muitos adultos que são, em sua maioria, pais, os quais veem nesses artefatos um suporte no processo de aprendizagem de seus filhos.

A partir da pesquisa, pode-se compreender que a mídia, enquanto pedagogia cultural, influencia, de forma direta, adultos e crianças em idade escolar. Isso porque eles possuem uma relação 
mútua de troca de aprendizagens que abrange também suas famílias e a escola, permeados pela cultura, conforme organograma criado pela autora, e apresentado ao lado.

Observa-se que as crianças vêm se tornando cada vez mais o centro de suas famílias e também o maior foco para o estímulo ao consumo exacerbado. Tudo isso pode ser visto como uma consequência diretamente relacionada à construção da identidade dessas crianças, que têm sido também influenciadas por pais que querem se tornar cada vez mais jovens, perdendo suas identidades de "pais seguros e autônomos" para outra, de "pais inseguros e dependentes".

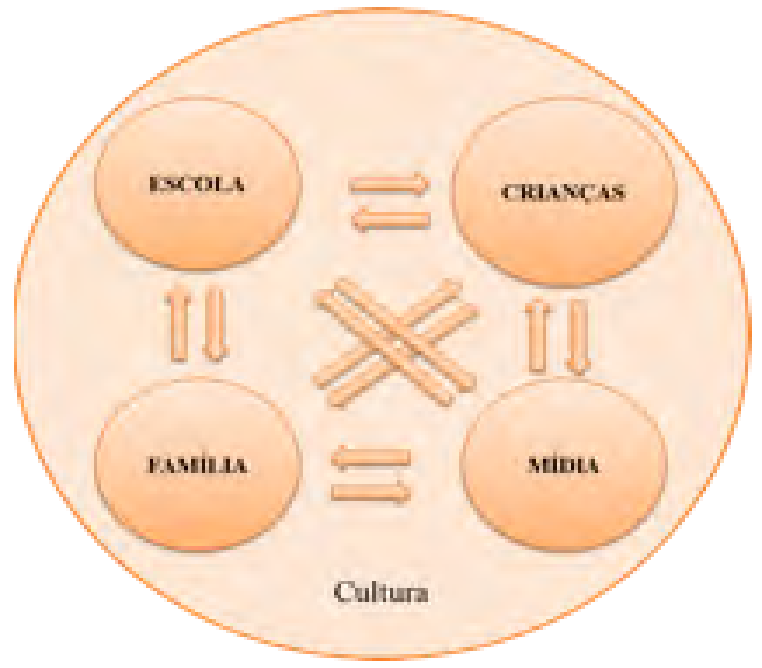

Figura 2- Relação de ensino e aprendizagem entre os meios analisados. Fonte: CAETANO, Marina. dora dos conhecimentos pessoais e do mundo, ainda deixa passar despercebida uma base teórica consistente para que se discutam os assuntos referentes ao consumo consciente e à adultilização da infância, não só em sala de aula, mas também no meio acadêmico, no qual os professores destas escolas vêm sendo formados.

\section{Considerações finais}

O objeto de estudo desta pesquisa foram as representações das crianças dos segundos e quartos anos do Ensino Fundamental I frente à temática da "adultilização da infância". Tema que vem ganhando cada vez mais notoriedade na academia tendo em vista o sentimento de que os jeitos típicos de ser criança vêm desaparecendo com o passar dos anos.

Tanto o referencial teórico, quanto a pesquisa de campo, através dos grupos focais, mostram que, por sua complexidade de desenvolvimento, comportamento e modo de socializar-se, a criança pode ser representada de várias formas. Isso abrange o conceito apresentado neste trabalho que, embora considerado como uma fase, "ser criança" constituirá diferentes infâncias, as quais são resultados de realidades díspares que estão em constante confronto.

Sabe-se ainda que a criança, mesmo que com muitos poderes de escolha, ainda não é maior de idade, não tem e não deve ter responsabilidades iguais as de um adulto, nem mesmo pode ser jul- 
gada como o mesmo perante as adversidades do meio social. Entende-se que toda criança, conforme a lei, está em um período de formação. Ela é um ser em desenvolvimento, que será constituído a partir de sua relação com o meio em que vive e com as instituições as quais frequenta. E tudo isso é permeado pelo fator cultural, o qual abrange tudo aquilo que é transmitido de geração para geração por grupos com determinados valores, crenças, práticas, instituições e identidades.

A velocidade com que emergem novas tecnologias tem permitido a incidência de outras instituições culturais que acabam por assumir o papel de educar e auxiliar na construção de identidades de todos os seres, sejam eles adultos, jovens ou crianças. As pedagogias culturais citadas nesta pesquisa remetem àquelas práticas educativas que se caracterizam por produzir valores tidos como culturais e são passados de geração para geração através de seus artefatos.

Dessa forma, as crianças hoje, estão mais informadas e conectadas à rede cada vez mais de maneira precoce, tendo acesso à grande maioria de artefatos culturais, adquirindo novos conhecimentos e mesclando seu comportamento infantil com características atribuídas ao comportamento adulto. Assim, não só os adultos passam a ser alvos da sociedade atual do consumo, mas também jovens e, principalmente, crianças.

A escola é um espaço onde as aprendizagens infantis se solidificam. Toda criança necessita passar por ela durante sua vida, e esse é um dos motivos que fazem da escola a maior instituição de ensino e aprendizagens formais atualmente. Enquanto pesquisadoras, notamos que, a partir das representações das crianças, grande parte das suas aprendizagens são construídas baseadas em experiências vivenciadas dentro da escola, mas que ela tem disputado esse lugar com os grandes objetos de mídia da atualidade.

A pesquisa realizada buscou partir do pressuposto de que as crianças possuem "voz" indo contra ao antigo conceito da "infantia", o qual tem como significado a "incapacidade de falar". Nesta pesquisa, deve ser ressaltado que a principal ferramenta metodológica utilizada privilegiou, além de uma pesquisa sobre crianças, uma pesquisa com as crianças, arriscando a deparar-se com o "desconhecido", sendo o mais desafiador e, ao mesmo tempo, vitorioso dos objetivos cumpridos.

As crianças, enquanto produtoras e reprodutoras a partir de suas interpretações das culturas com as quais vivem e convivem, constroem suas identidades de diferentes maneiras a partir de representações produzidas e veiculadas pelos artefatos tanto quanto pelas situações que vivenciam no 
cotidiado da vida em sociedade. Percebemos que crianças tão pequenas, de sete anos e outras, um pouco maiores, de 10 anos, já demonstram desejos de consumir produtos, corpos com contornos estéticos considerados padrões na sociedade - e fazer exercícios com este intuito, roupas fashion, "fazer chapinha", "luzes" ou "pintar as unhas", mas que também há um percentual significativo de crianças que gostam e vivem suas infâncias de forma típica - relacionando-se com seus pares através de jogos e brincadeiras.

Anteriormente já foi dito e cabe reforçar que as crianças pesquisadas neste trabalho, embora tenham um perfil consumista e dominador, ainda se enxergam como crianças típicas, pois preferem o brincar ao comprar e possuem uma consciência universal de que é preciso pensar sobre as necessidades de se consumir "aquilo naquele momento". Entretanto, é perceptível que há diferenças entre os alunos dos segundos e dos quartos anos.

É interessante observar que as crianças já conseguem dizer e classificar o que é apropriado para elas e para os adultos. Meninos e meninas, desde tão novos, são incentivados a questionar-se sobre tais fatos impulsionados, na maioria das vezes, por certas representações culturais, principalmente da mídia, da escola e da família, a decidir o que usar ou seus modos de agir. Dessa forma, vê-se o quanto tais meios estão envolvidos em redes de regulação, que propagam representações e discursos específicos, orientando posturas e definindo modos de olhar e vestir-se, não só vendendo o que está anunciado, mas criando um imaginário sensual e desejável que é, por vezes, entendido de forma naturalizada e universal a fim de que todos ajam e sejam homônimos.

Sobre essa naturalização, é possível perceber que, mesmo que possuam um olhar crítico, as crianças, dificilmente, conseguem julgar como “fora do padrão" aquelas meninas e meninos que são adultilizados e erotizados pela mídia. Ver esse tipo de anúncio tornou-se algo banal, que faz parte da cultura e fará parte, indiscutivelmente, da construção das identidades infantis.

É imprescindível refletir sobre como esses ensinamentos chegam à vida das crianças todos os dias. Para isso, pensa-se ser fundamental que toda a escola, seja de Educação Infantil ou de Ensino Fundamental, favoreça a abertura de espaços para discussão e problematização de todos envolvidos na educação e formação das crianças, principalmente no que diz respeito a sua proximidade cada vez maior com os artefatos midiáticos.

A escola, a família e a sociedade, como um todo, tem a responsabilidade na formação das 
crianças. Por isso, devem focar sua atenção aos impactos impostos pelas representações sociais conduzidas pela mídia, como forma de preservar valores infantis e conceitos que possam prejudicar seu desenvolvimento, que ocorrerá de maneira precoce, descaracterizando a infância e transformando todos em adultos em miniatura.

Em respeito aos referenciais teóricos utilizados, entende-se que este trabalho não buscou apresentar aos leitores respostas conclusivas e unidirecionais, mas sim uma problematização e discussão a respeito das representações dos alunos de segundos e quartos anos do Ensino Fundamental a respeito da adultilização na infância.

\section{Referências}

ARIÉS, P. História social da criança e da família. Trad. Dora Flaksman. 2.ed. Rio de Janeiro: Livros Técnicos e Científicos, 1981.

BARBOSA, Maria Carmen Silveira. Culturas escolares, culturas de infância e culturas familiares: as socializaçóes e a escolarizaçáo no entretecer destas culturas. Educação \& Sociedade, Campinas, v. 28, n. 100 - Especial, p. 1059-1083, out. 2007.

BAUMAN, ZYGMUNT. Vida para consumo. Rio de Janeiro: Ed. Zahar, 2008.

BORGES, Eliane Medeiros. Corpo, espetáculo e consumo: novas configuraçôes midiáticas para a infância. In. Media \& Jornalismo. Juiz de Fora: 2007, (II) pp. 91-103. Disponível em: <http:// www.revistas.univerciencia.org/index.php/mediajornalismo/article/viewFile/5795/5250>. Acesso em: 16 mar. 2015.

BRASIL. Estatuto da criança e do adolescente: Lei federal no 8069, de 13 de julho de 1990. Rio de Janeiro: Imprensa Oficial, 2002.

COHN, C. Antropologia da criança. Rio de Janeiro: J. Zahar, 2005.

CORSARO, William A. Sociologia da infância. 2.ed. Porto Alegre, RS: Artmed, 2011.

DORNELLES, Leni Vieira; BURJES, Maria Isabel Edelweiss (org.). Educação e infância na era da informaçáo. Porto Alegre, RS - Mediação, 2012.

FELIPE, Jane. Entre tias e tiazinhas: Pedagogias Culturais em circulação. In: SILVA, Luiz Heron (org.). Século XXI: Qual conhecimento? Qual currículo? Petrópolis: Vozes, 1999.

FELIPE, Jane. Construindo identidades sexuais na Educaçáo Infantil. Porto Alegre: Páteo, n. 7, p. 56-58, nov.98/jan. 99.

FELIPE, Jane. Infância, gênero e sexualidade. Educação e Realidade 25(1):115-131, jan./jun. 2000.

FELIPE, Jane. "Cachorras", “tigróes” e outros "bichos": problematizando gênero e sexualidade no contexto escolar. In: Fazendo escola, v. 02, 2002. p. 26-30.

FELIPE, Jane; GUIZZO, Bianca Salazar. A erotizaçáo dos corpos infantis na sociedade de 
consumo. In Pro-Posiçóes. V.14, n.3 (42) set/dez.2003.

FELIPE, Jane. Afinal, quem é mesmo pedófilo? Cadernos Pagu (26), Núcleo de Estudos de Gênero - Pagu/Unicamp, 2006, pp.201-223.

FELIPE, Jane. Representaçôes de gênero, sexualidade e corpo na mídia. Revista Tecnologia e Sociedade, 2007.

FELIPE, Jane. Erotizaçáo dos corpos infantis. In: LOURO, Guacira Lopes; et allii (org.) Corpo, gênero e sexualidade: um debate contemporâneo na educação. 5 Ed. Petrópolis: Vozes, 2010.

Ferreguett, Cristhiane. Relaçóes dialógicas em revista infantil: processo de adultização de meninas. Dissertação (Doutorado). Pontifícia Universidade do Rio Grande do Sul. Porto Alegre, RS, 2014.

FERREIRA, Aurélio Buarque Holanda. Mini Aurélio: o mini dicionário da língua portuguesa. 4. ed. rev. e ampl. Rio de Janeiro: Nova Fronteira, 2001

FILHO, Altino José Martins; BARBOSA, Maria Carmem Silveira. Revista Reflexáo e Açáo, Santa Cruz do Sul, v.18, n2, p.08-28, 2010.

FISCHER, Rosa. Identidade, cultura e mídia: a complexidade de novas questóes educacionais na contemporaneidade. In: SILVA, Luiz Heron (Org.). Século XXI: qual conhecimento? Qual currículo? Petrópolis: Vozes, 1999, p. 18-32.

GOELLNER, Silvana Vilodre (org.). Corpo, gênero e sexualidade: um debate contemporâneo na educação. Petrópolis: Vozes, 2011, 7. ed, p. 53-65.

GONÇALVES, M. F. Currículo Oculto e Culturas de aprendizagem na formação de professores. Porto Alegre: Artmed, 1994.

LANDINI, Tatiana Savóia. Pornografia infantil na Internet: proliferação e visibilidade. 2000. Dissertação (Mestrado) FFCH/USP - São Paulo.

LOURO, Guacira Lopes; FELIPE, Jane; GOELLNER, Silvana Vilodre (Org.). Corpo, gênero e sexualidade: um debate contemporâneo na educação. 6. ed. - Petrópolis, RJ: Vozes, 2010.

LOURO, Guacira Lopes. Gênero, sexualidade e educação: Uma perspectiva pós-estruturalista. 16.ed. - Petrópolis, RJ: Vozes, 2004.

MEYER, Dagmar. As mamas como constituintes da maternidade: uma história do passado? Educação e Realidade. Porto Alegre: FACED/UFRGS, v. 25, n. 2, jul./dez. 2000, p. 117- 134.

MORIN, E. Cultura de massa no século XX: neurose. 10 ed. Rio de Janeiro: Forense Universitária, 2011. v. 1.

ORLANDI, Rosângela Gisoldi. A representação social da criança em anúncios de moda na revista Vogue Kids Brasil. 2012. Dissertação (Mestrado). Universidade Municipal de São Caetano do Sul - São Caetano do Sul.

PINTO, Manoel; SARMENTO, Manoel Jacinto (Org). As Crianças e a Infância: definindo conceitos, delimitando campos. In: As crianças: contexto e identidades. Braga, Portugal: Centro de Estudos da Criança, 1997.

QUADRADO, Raquel Pereira; RIBEIRO, Paula Regina. O corpo na escola: alguns olhares sobre 
o currículo. Revista Enseñanza de las Ciencias, v. Extra, p. 1-5, 2005. Disponível em: <http:// ddd.uab.cat/pub/edlc/02124528v2005nE/02124528v2005nE127coresc.pdf>. Acesso em: 16 Nov, 2011.

SARMENTO, Manoel Jacinto. A Globalização e a Infância: impactos na condição social e na escolarização. In: GARCIA, Regina Leite \& LEITE Aristeo Filho (orgs.). Em defesa da educação infantil. Rio de Janeiro: DPEA, 2001, P. 13 - 28.

SARMENTO, Manuel Jacinto. Gerações e alteridade: interrogaçóes a partir da sociologia da infância. Educ. Soc. [online]. 2005, vol.26, n.91, pp. 361-378. <http://dx.doi.org/10.1590/S0101$73302005000200003>$. Acesso em 19 fev. 2016.

SILVA, Tomaz Tadeu da. Documentos de identidade: uma introduçáo às teorias do currículo. 2. ed. 4. reimp. Belo Horizonte: Autêntica, 2002.

SIROTA, Régine. Emergência de uma Sociologia da Infância: evolução do objeto e do olhar. Cadernos de Pesquisa, São Paulo, no 112, pp.7-31, mar. 2001.

WOODWARD, K. (2012) Identidade e diferença: uma introdução teórica e conceitual. EM: SILVA, T. T. Identidade e diferença: a perspectiva dos estudos culturais. Capítulo 1, pp. 7-72. Petrópolis: Vozes. 